\title{
Collective Marketing Arrangements for Geographically Differentiated Agricultural Products: Welfare Impacts and Policy Implications
}

\author{
Sergio H. Lence, Stéphan Marette, Dermot J. Hayes, and William Foster
}

MATRIC Working Paper 06-MWP 9

May 2006

\author{
Midwest Agribusiness Trade Research and Information Center \\ lowa State University \\ Ames, lowa 50011-1070 \\ www.matric.iastate.edu
}

Sergio Lence is a professor of economics at lowa State University. Stéphan Marette is with the UMR Economie Publique, Institut National de la Recherche Agronomique (INRA), INAPG, and is a visiting scholar at CARD, lowa State University. Dermot Hayes is Pioneer Hi-Bred International Chair in Agribusiness and a professor of economics and of business at lowa State University. William Foster is a professor at the Universidad Católica in Santiago.

Available online on the MATRIC Web site: www.matric.iastate.edu. Permission is granted to reproduce this information with appropriate attribution to the authors.

Questions or comments about the contents of this paper should be directed to Stéphan Marette, e-mail: marette@iastate.edu or marette@inapg.fr.

MATRIC is supported by the Cooperative State Research, Education, and Extension Service, U.S. Department of Agriculture, under Agreement No. 92-34285-7175. Any opinions, findings, conclusions, or recommendations expressed in this publication are those of the authors and do not necessarily reflect the view of the U.S. Department of Agriculture.

The U.S. Department of Agriculture (USDA) prohibits discrimination in all its programs and activities on the basis of race, color, national origin, gender, religion, age, disability, political beliefs, sexual orientation, and marital or family status. (Not all prohibited bases apply to all programs.) Persons with disabilities who require alternative means for communication of program information (Braille, large print, audiotape, etc.) should contact USDA's TARGET Center at (202) 720-2600 (voice and TDD). To file a complaint of discrimination, write USDA, Director, Office of Civil Rights, Room 326-W, Whitten Building, 14th and Independence Avenue, SW, Washington, DC 20250-9410 or call (202) 720-5964 (voice and TDD). USDA is an equal opportunity provider and employer. 


\begin{abstract}
This paper examines the incentive of atomistic agricultural producers within a specific geographical region to differentiate and collectively market products. We develop a model that allows us to analyze the market and welfare effects of the main types of real-world producer organizations, using it to derive economic insights regarding the circumstances under which these organizations will evolve, and describing implications of the results obtained in the context of an ongoing debate between the European Union and United States. As the anticipated fixed costs of development and marketing increase and the anticipated size of the market falls, it becomes essential to increase the ability of the producer organization to control supply in order to ensure the coverage of fixed costs. Whenever a collective organization allows a market (with a new product) to exist that otherwise would not have existed there is an increase in societal welfare. Counterintuitively, stronger property right protection for producer organizations may be welfare enhancing even after a differentiated product has been developed. The reason for this somewhat paradoxical result is that legislation aimed at curtailing the market power of producer organizations may induce large technological distortions.
\end{abstract}

Keywords: agricultural products, collective promotion, geographic indications, supply control, quality. 


\section{Introduction}

We explore the microeconomic foundations and welfare implications of various mechanisms designed to encourage agricultural producers to geographically differentiate and collectively market their products. The atomistic structure of agricultural production creates a much different incentive structure than exists in sectors of the economy where single firms own and market individual brands. Because forward-looking producers recognize that other producers within the group will expand production in response to any price premium associated with their marketing efforts, alternative mechanisms including supply control are often necessary to encourage producers to pay the up-front costs of differentiating their products. We study market outcomes under various organizational structures that differ according to the intensity of supply control.

Producers evaluate whether to establish the new organization based on the legal environment and the anticipated gains from doing so, relative to the fixed costs associated with developing and marketing the new product. We refer to the output of these legally established collective organizations as Geographically Differentiated Agricultural Products (GDAPs). We use the term "commodity" to describe the undifferentiated product that can be produced and marketed even in the absence of a producer organization.

We focus on organizations controlling (and restricting) either (i) the amount of land devoted to the GDAP, or (ii) the production practices that are used to produce the GDAP, or (iii) both the amount of land and the production practices. We rank these various types of organizations in terms of their contribution to producer and social welfare. We also compare these structures to the perfectly competitive case, the monopoly or firm-specific brand case, and the unrestricted Pareto optimal solution (i.e., a social planner scenario). 
Our results indicate that as the anticipated fixed costs of GDAP development and marketing increase, it becomes essential to increase the ability of the producer organization to control supply in order to ensure the emergence of the GDAP. Whenever a GDAP organization allows a market (with a new product) to exist that otherwise would not have existed there is an increase in societal welfare. However, whenever an organization exerts more supply control than is needed to create the GDAP, there may be a reduction in total welfare compared to organizations with less market power.

Importantly, we show that legislation aimed at curbing a producer organization's anticompetitive behavior may lead to reduced social welfare, even after a GDAP has been developed. This situation may occur because such legislation will often induce the producer organization to select inefficient technologies in its attempt to exploit the opportunities to exercise market power to the extent allowed by the law.

While there are several theoretical papers on grading and labeling in agriculture, very few papers have theoretically examined the link between quality decisions and supply control by farmers. Hollander, Monier, and Ossard (1999) show the complexity of the farmers' incentives for certifying products. In particular, they show that high-quality firms may have a lower proportion of their output certified than the low-quality firms. Marette and Crespi (2003) focus on a farmers' cartel that emerges when certification costs are large and show that the benefit of the certification outweighs the negative effect arising from the price distortion when the product differentiation is sufficiently large. Zago and Pick (2004) study the effects of labels and emphasize the negative welfare effects of labels when administrative costs are high, quality differences are small, and/or costs differences are high. 
Our article departs from these previous articles in that we analyze alternative types of organizations that are tailored to represent a wide spectrum of farm organizations that exist in the real world. We focus on details regarding different types of supply control, such as a land restriction and/or restrictive production technologies. We also include in our model the supply response that occurs within these organizations as atomistic member producers respond to price premiums.

The incentives that are created by these organizational structures are unique to agriculture in two ways. First, any price-enhancing effect generated by the organization provides each atomistic producer within the organization with an incentive to move up and out along his marginal cost curve, a factor that is not important in other forms of imperfect competition. Second, the welfare impact of GDAPs depends very much on the ability of the organization to control supply and the proportion of total production over which this control is provided. This issue is unique to agriculture, again because the number of producers within the relevant geography is such that each individual producer bears none of the costs associated with his expansion of output.

The present paper contributes to the literature by providing a model to analyze the market and welfare effects of the main types of real-world GDAP organizations, using it to derive economic insights regarding GDAPs, and describing implications of the results obtained in the context of an ongoing debate between the EU and U.S. We proceed first by describing alternative producer organizations, and then present the formal model. The main results are subsequently presented and discussed, followed by a description of the real-world implications of these results. 


\section{GDAP Organizations}

The first structure examined is one in which the producer organization managing the GDAP is prevented from controlling supply in any way. An example of this situation might include Idaho potatoes in the U.S. The second structure analyzed is at the opposite end relative to the first one in terms of competitive behavior and provides the organization managing the GDAP with complete market power. ${ }^{1}$ This case is included for comparison purposes only, because we are not familiar with any producer organization that is allowed to possess this type of market power because of antitrust concerns. However, the situation we describe is isomorphic to the one faced by any firm-specific corporate food brand that obtains its commodity input via contract production or from within the organization, such as that for corn flakes or frozen vegetables.

The third type of structure under study allows the organization that manages the GDAP to control both the amount of land and the production practices that are used to produce the GDAP. In this instance, individual producers are free to select the amounts of inputs other than land, but they can only use the land stipulated by the organization, and they must conform to the regulations on production practices determined by the organization. The GDAP that best represents this case is the Brunello di Montalcino described in Hayes, Lence, and Stoppa (2004). The consortium that protects this GDAP has the power to limit the total amount of land eligible for grape production and to restrict the ability of producers to expand production on these limited acres (e.g., by forbidding the use of irrigation).

In the fourth structure, the GDAP organization has the power to control the total amount of land allocated to the GDAP but not the production practices. Except for the restriction on land, individual producers can choose inputs and practices to produce the GDAP. An example of this

\footnotetext{
${ }^{1}$ To avoid having individual producer members increase output levels in response to any price premia that is generated, the organization also provides each producer with a fixed production quota.
} 
type of structure is the "Lentils from Castelluccio di Norcia" described in Hayes, Lence, and Stoppa.

The fifth and final structure analyzed is such that the organization has control over the production practices but not over the land area used to produce GDAP. Other than adhering to the production procedures set up by the organization, individual producers can select the desired amounts of all inputs to obtain the GDAP. This scenario is similar to some U.S. marketing orders, where grade and quality standards are used to both improve quality and remove excess output from the market. An example is Order 993 that authorizes grade, size, pack, market allocation, reserve pool, as well as inspection requirements to organize the market for California dried prunes (USDA 2006).

\section{The Model}

To focus attention on the essential issues previously discussed, our model is as simple and as general as possible while depicting the essential characteristics of the GDAP organizational structure. The model does not introduce any uncertainty about the success of the GDAP. Producers are assumed to know that if they are willing to spend a specific amount on product and market development, they will achieve a market of known size for the GDAP.

As shown in Figure 1, the model assumes three points in time. At time $t=0$, policy makers set up laws to regulate the structure and competitive behavior of producer organizations. At time $t=1$, commodity producers in a particular, and most likely those in a favored, production area must decide whether a GDAP should be developed. If producers decide to proceed with the GDAP, at time $t=2$ they establish a legal organization that invests an amount $K$ of fixed costs to develop the GDAP and its market (e.g., to make potential consumers aware of 
and willing to pay a premium for it), and at time $t=3$ the GDAP is produced and consumed.

Otherwise, no fixed costs are incurred to develop the GDAP at $t=2$, and only the commodity is produced and consumed at time $t=3$.

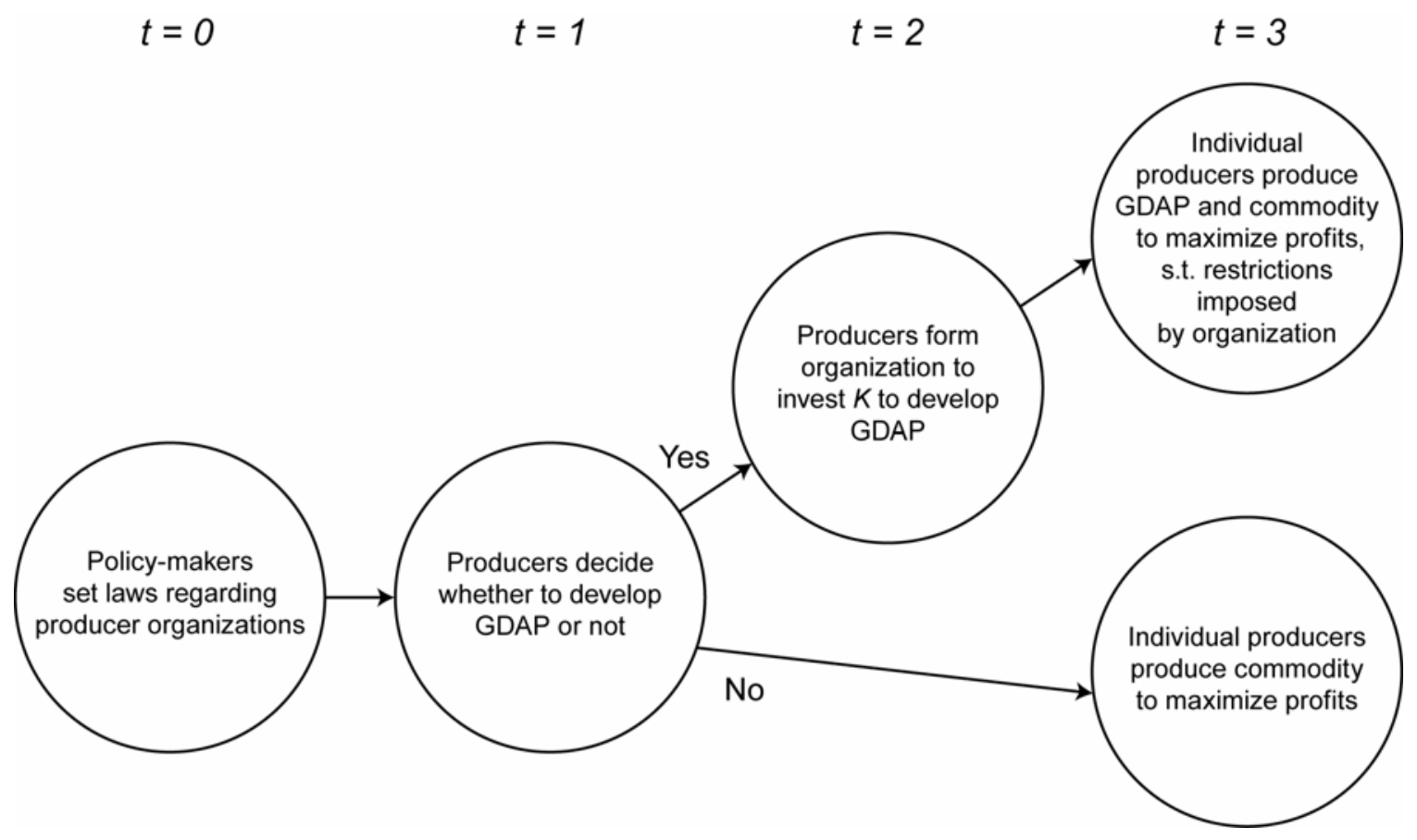

\section{Figure 1. Timing Framework for the Analysis}

At time $t=1$, producers decide whether to proceed or not by comparing the net benefits from developing the GDAP against the baseline of continued commodity production. As shown later, the net benefits to producers and society from developing the GDAP depend crucially on the type of producer organization involved. Producers have a vested interest in establishing the organization that yields the greatest producer surplus, but existing laws (e.g., antitrust rules) may prevent them from doing so. Hence, the producer organization formed at time $t=2$ is assumed to be the one that yields the greatest possible producer surplus within the existing legal environment, and the producers' decision at time $t=1$ is based on such an assumption. Clearly, 
the type of producer organization that can be legally formed may greatly affect whether the GDAP is developed and may lead to substantially different welfare outcomes for society. The various possible alternative organizations are examined after describing GDAP consumption and production in the next subsection.

\subsection{GDAP Consumption and Production}

Market development activities undertaken at time $t=2$ (see Figure 1) yield a representative consumer with quasilinear utility $U\left(X, X_{N u m}\right) \equiv u(X)+X_{\text {Num }}$ subject to the budget constraint $M=$ $P X+X_{N u m}$, where $X$ and $X_{\text {Num }}$ denote aggregate consumption of the GDAP and a numéraire good, respectively; $M$ is the consumer's wealth; $P$ represents the price of the GDAP; and $u(\cdot)$ is a differentiable function with $u^{\prime}(\cdot)>0, u^{\prime \prime}(\cdot)<0$, and $\lim _{X \rightarrow 0} u^{\prime}(X)=\infty$. $^{2}$ Using the budget constraint to obtain $X_{N u m}=M-P X$, and plugging the resulting expression into the utility function to get $U(X, M-P X)=u(X)+M-P X$, the first-order necessary condition (FOC) corresponding to optimal GDAP consumption is $\partial U^{*} / \partial X=u^{\prime}\left(X^{*}\right)-P=0$. This yields the inverse demand function (3.1) and consumer surplus (3.2), respectively:

$$
P=u^{\prime}\left(X^{*}\right)
$$

$$
\operatorname{cs}\left(X^{*}\right) \equiv M+u\left(X^{*}\right)-u^{\prime}\left(X^{*}\right) X^{*}
$$

\footnotetext{
${ }^{2}$ The assumption that $\lim _{X \rightarrow 0} u^{\prime}(X)=\infty$ is imposed only for convenience, because it ensures strictly positive aggregate production and consumption of the GDAP at time $t=2$, conditional on development of the GDAP at $t=1$. This is the only case of interest for the present study. The case of zero aggregate production and consumption of GDAP at $t$ $=2$ is not very illuminating, as it implies that it would never be optimal to develop the GDAP at $t=1$.
} 
The potential producers of the GDAP consist of a small subset of all commodity producers, so that they face a perfectly elastic demand for the commodity at price $P_{\text {com. }}{ }^{3}$ We have in mind a group of producers located in an area that is favored with the characteristics required to produce a superior product, or at least convince consumers that the product from that area is somehow worth a price premium. This may be due, for example, to unique environmental conditions characterizing their region, or it may also be due to much lower input costs for some quality-enhancing input in that region.

All producers within the region are assumed to be identical. They control an aggregate farmland area of $A$ acres and can produce the commodity with a technology characterized by constant returns to scale in the land input and decreasing returns to scale in other variable inputs. Thus, if they devote all of their land to produce the commodity, profits per acre are represented by $\pi_{c o m} \equiv P_{c o m} x_{c o m}-c\left(x_{c o m} ; \theta=1\right)$, where $x_{c o m}$ is the commodity output per unit of land, and $c(\cdot)$ $\geq 0$ is a variable cost function satisfying the conditions $c(0 ; \theta)=0, c_{1}(\cdot)>0$, and $c_{11}(\cdot)>0$. Parameter $\theta \geq 1$ is included in the cost function because it will prove important to analyze GDAPs. At this point, it suffices to state that $\theta$ is normalized at its minimum possible value of $\theta$ $=1$ for the commodity product.

By applying standard optimization techniques, it is straightforward to show that, conditional on producing commodity only; maximum profits per acre are given by (3.3):

$$
\pi_{\text {com }}^{*} \equiv P_{\text {com }} x_{\text {com }}^{*}-c\left(x_{\text {com }}^{*}, 1\right)
$$

\footnotetext{
${ }^{3}$ The stated assumptions render the behavior of producers (consumers) who can only supply (consume) the commodity product irrelevant for the purposes of the present study. Hence, to save space, in the remainder of the paper the term producers (consumers) will refer to the potential producers (consumers) of the GDAP.
} 
where $x_{\text {com }}^{*}=c_{1}^{-1}\left(P_{\text {com }}, 1\right)$ is the optimal commodity output per acre and $c_{1}^{-1}(\cdot, 1)$ denotes the inverse function of $c_{1}(\cdot, 1)$. Therefore, if at time $t=1$ the decision is to not develop the GDAP, the maximum producer surplus evaluated at time $t=3$ is $\left(A \pi_{c o m}^{*}\right)$. That is, producer surplus equals the total number of farmland acres times the maximum commodity profits attainable per acre under perfect competition.

If the GDAP is developed, per-acre costs of producing $x$ units of GDAP are given by $c(x$, $\theta$ ) for $\theta \geq \underline{\theta} \geq 1$, and the existing technology used to produce the commodity is not affected (i.e., per-acre commodity costs remain at $\left.c\left(x_{c o m}^{*}, 1\right)\right)$. Both variable costs and marginal costs are assumed to be increasing in parameter $\theta$, i.e., $c_{2}(x>0, \theta)>0$ and $c_{12}(\cdot)>0$, respectively. Parameterization of the variable cost function in terms of $\theta$ is meant to serve two purposes. First, $\underline{\theta}>1$ represents the realistic situations where it is more expensive to produce the GDAP than to produce the commodity. Second, $\theta$ provides us with a straightforward way to model producer organizations that impose regulations to increase GDAP costs above what the latter would be otherwise. Such scenarios can be represented by organizations mandating a value for $\theta$ larger than the minimum technically feasible $\underline{\theta}$ (e.g., by enforcing stricter-than-necessary GDAP production requirements such as a ban on irrigation). In the cases where $\theta$ is the only tool for the GDAP organization to adjust output levels, this parameter can be interpreted as a quality adjustment to reduce the proportion of total GDAP output that can be marketed.

Producer surplus at time $t=3$ conditional on the GDAP having been developed at $t=2$ is therefore given by $\left\{A a[P x-c(x, \theta)]+A(1-a) \pi_{c o m}^{*}\right\}$, where $a \in(0,1)$ is the share of 
farmland devoted to GDAP production. ${ }^{4}$ That is, producer surplus equals the acres used to produce the GDAP $(A a)$ times GDAP profits per acre $[P x-c(x, \theta)]$, plus the acres employed to produce commodity $[A(1-a)]$ multiplied by per-acre maximum commodity profits $\left(\pi_{c o m}^{*}\right)$. Since producer surplus is $\left\{A a[P x-c(x, \theta)]+A(1-a) \pi_{c o m}^{*}\right\}$ if the GDAP is developed at time $t=2$, and $\left(A \pi_{c o m}^{*}\right)$ otherwise, the net change in producer surplus resulting from the introduction of the GDAP (evaluated in monetary units of time $t=3$ ) is (3.4):

\section{(3.4) $\Delta p s=A \Delta \pi$.}

In (3.4), $\Delta \pi \equiv a\left\{[P x-c(x, \theta)]-\pi_{c o m}^{*}\right\}$ is the change in average profits per acre from using a farmland share of $a$ to produce the GDAP instead of the commodity. According to (3.4), conditional on having developed the GDAP at $t=2$, producers will gain an amount equal to the per-acre profit difference from producing the GDAP instead of the commodity, multiplied by the number of acres used to produce the GDAP.

As shown later, the change in producer surplus (3.4) may be greatly affected by the type of producer organization, as such organizations may adopt rules affecting both profits per acre $[P$ $x-c(x, \theta)]$ and the proportion of land allocated to the GDAP $(a)$. Such organizations will be examined following the next section's discussion of the benchmark case of the Pareto optimal decision regarding development of the GDAP.

\footnotetext{
${ }^{4}$ Note that $\pi_{\text {com }}^{*}$ was substituted for $\pi_{\text {com }}$ in the producer surplus expression to streamline the presentation. The substitution is warranted because all of the producer-surplus-maximizing mechanisms to be discussed later imply maximization of per-acre commodity profits, and the latter equal $\pi_{\text {com }}^{*}$ due to the assumption of perfectly elastic commodity demand.
} 


\subsection{A Social Planner's Decision Regarding Development of the GDAP}

From a societal perspective, the GDAP should be developed if the gains to society from doing so exceed the associated costs. If the GDAP is not developed, then only the commodity can be produced at time $t=3$, and the optimal commodity output for society is the same as under perfect competition. That is, provided the GDAP is not developed at time $t=2$, the relevant societal surplus at time $t=3$ is given by $\left(A \pi_{c o m}^{*}\right) .{ }^{5}$ On the other hand, if the GDAP is developed at $t=2$, societal surplus at $t=3$ consists of the surplus from the GDAP $[M+u(A a x)-A$ a $c(x, \theta)]$ plus the surplus from the commodity $\left[A(1-a) \pi_{c o m}^{*}\right]$. Therefore, conditional on the GDAP having been developed at time $t=2$, the net change in societal welfare stemming from the development of the new product (measured in monetary units of time $t=3$ ) is (3.5):

$$
\begin{aligned}
\Delta s s= & M+u(A a x)-A a\left[c(x, \theta)+\pi_{c o m}^{*}\right], \\
= & c s(A a x)+\Delta p s,
\end{aligned}
$$

where $u(A a x)$ represents the benefits from consuming the GDAP output obtained by employing (A a) acres to produce GDAP at the rate of $x$ units per acre, and $A$ a $c(x, \theta)$ and $A$ a $\pi_{c o m}^{*}$ are the associated total variable costs and total opportunity costs, respectively. Expression (3.5') is derived by noting that $(P A$ a $x=P X)$ is simply a transfer payment from consumers to producers that takes place in a market economy.

\footnotetext{
${ }^{5}$ Note that the relevant consumer surplus is zero because by assumption the group of producers under investigation has negligible mass relative to the entire commodity market, so the corresponding demand is infinitely elastic at price $P_{\text {com }}$.
} 
The FOCs for a social planner's optimal choice of $x, a$, and $\theta$ to maximize (3.5) are

$$
\frac{\partial \Delta s S^{S P}}{\partial x}=A a^{S P} u^{\prime}\left(A a^{S P} x^{S P}\right)-A a^{S P} c_{1}\left(x^{S P}, \theta^{S P}\right)=0
$$

$$
\frac{\partial \Delta s S^{S P}}{\partial a}=A\left[x^{S P} u^{\prime}\left(A a^{S P} x^{S P}\right)-c\left(x^{S P}, \theta^{S P}\right)-A \pi_{c o m}^{*}-\lambda_{a \leq 1}^{S P}=0\right.
$$

$$
\frac{\partial \Delta s s^{S P}}{\partial \theta}=-A a^{S P} c_{2}\left(x^{S P}, \theta^{S P}\right)+\lambda_{\theta \geq \underline{\theta}}^{S P}=0
$$

where superscript "SP" denotes optimal values from a social planner's standpoint, and $\lambda_{a \leq 1}^{S P}$ and $\lambda_{\theta \geq \underline{\theta}}^{S P}$ are the Lagrangian multipliers corresponding to the constraints $a \leq 1$ and $\theta \geq \underline{\theta}$, respectively. $^{6}$

At the optimum, the increase in utility from raising GDAP output per acre by one unit should be equal to the associated increase in production costs (see (3.6)). According to (3.7), a social planner expands the share of acres devoted to GDAP production up to the point where the last acre used to produce the GDAP yields the same net benefit as switching this acre into commodity production. All acres should be used for the GDAP (commodity) if the marginal net benefits from the GDAP evaluated at $a=1(0)$ exceed (are less than) the marginal net benefits from the commodity. Finally, from (3.8) it is clear that the optimum value of $\theta$ is $\theta^{S P}=\underline{\theta}$. This is as expected, because increasing $\theta$ means higher costs, which can never be beneficial for society as a whole. ${ }^{7}$

${ }^{6}$ FOCs corresponding to the constraints are straightforward and are omitted to save space.

${ }^{7}$ It will be shown later, however, that increasing $\theta$ may allow producers to gain at the expense of consumers. 
From the perspective of society, the GDAP should (not) be developed if $\Delta s s^{S P}>(<) \hat{K}$, where $\hat{K}$ equals $K$ times a capitalization factor that corrects for the time value corresponding to the interval elapsed between times $t=2$ and $t=3$. Therefore, $\hat{K}^{S P} \equiv \Delta s S^{S P}$ defines the fixed development cost that makes the social planner indifferent about developing the GDAP. The net change in social surplus corresponding to the optimal social planner's decision is $\Delta S S^{S P}(\hat{K})=$ $1_{\hat{K}<\hat{K}^{S P}}\left(\Delta s S^{S P}-\hat{K}\right)$, where $1_{\text {condition }}$ is the indicator function (equal to 1 if "condition" is satisfied, and 0 otherwise). That is, if fixed development costs are too high $\left(\hat{K}>\hat{K}^{S P}\right)$, developing the GDAP has a net negative impact on societal welfare $\left(\Delta s s^{S P}-\hat{K}<0\right)$, so the optimal social planner's decision is to not develop it, in which case society's welfare is unchanged [ $\Delta S S^{S P}(\hat{K})$ $=0]$. Otherwise, if fixed development costs are sufficiently low $\left(\hat{K}<\hat{K}^{S P}\right)$, society benefits from development of the GDAP $\left(\Delta s s^{S P}-\hat{K}>0\right)$, so the optimal social planner's decision is to invest in it and society's welfare improves as a result $\left[\Delta S S^{S P}(\hat{K})=\Delta s S^{S P}-\hat{K}>0\right]$.

\subsection{GDAP Organizations with Alternative Degrees of Supply Control}

The main role of the producer organization is to develop the GDAP and to control supply so as to maximize producer surplus within the confines of the law. Since the extent to which the behavior of producer organizations is regulated and anticompetitive practices are limited varies across legal jurisdictions, we proceed by assuming that producers will focus on the organization that yields the greatest producer surplus allowed by the law. We first discuss the polar cases of perfect competition and non-discriminating monopoly and then address three cases displaying supply controls in between those two extremes. 


\subsubsection{Case 1: Perfect Competition}

In the polar case of perfect competition, existing laws prevent the producer organization from exerting any type of supply control. Therefore, if the GDAP is developed, individual producers maximize profits by selecting the optimal levels of per-acre GDAP output, the share of farmland devoted to GDAP production, and $\theta$ while receiving a competitive price for their GDAP output. Under such restrictions, the market-clearing FOCs for the maximum average change in profits per acre $(\Delta \pi)$ provided the GDAP is introduced at time $t=2$ are (3.9) through (3.11):

$$
\frac{\partial \Delta \pi^{P C}}{\partial x}=a^{P C}\left[u^{\prime}\left(A a^{P C} x^{P C}\right)-C_{1}\left(x^{P C}, \theta^{P C}\right)\right]=0,
$$

$$
\frac{\partial \Delta \pi^{P C}}{\partial a}=\left[x^{P C} u^{\prime}\left(A a^{P C} x^{P C}\right)-c\left(x^{P C}, \theta^{P C}\right)\right]-\pi_{c o m}^{*}-\lambda_{a \leq 1}^{P C}=0
$$

$$
\frac{\partial \Delta \pi^{P C}}{\partial \theta}=-a^{P C} C_{2}\left(x^{P C}, \theta^{P C}\right)+\lambda_{\theta \geq \underline{\theta}}^{P C}=0
$$

In the FOCs above, superscript " $P C$ " denotes optimal values under perfect competition. Note that FOCs are being evaluated at the market-clearing output and consumption quantities, so that aggregate supply ( $A a x)$ equals aggregate demand $(X)$ and the GDAP price is given by (3.1).

Comparison of (3.6)-(3.8) with (3.9)-(3.11) reveals that the latter are identical to the former multiplied by $A>0$. Therefore, when the new GDAP is developed, equilibrium allocations under perfect competition are optimal from a societal standpoint, i.e., $x^{P C}=x^{S P}, a^{P C}=$ $a^{S P}$, and $\theta^{P C}=\theta^{S P}=\underline{\theta}$, so that $\Delta s s^{P C}=\Delta s s^{S P}$. However, from the producers' perspective, the 
decision whether to develop the GDAP hinges upon whether there is a net gain in producer surplus. That is, the producer organization's indifference level of investment is $\hat{K}^{P C} \equiv \Delta p s^{P C}$. But it is clear from (3.5) that $\hat{K}^{P C}=\hat{K}^{S P}-\operatorname{cs}\left(A a^{S P} x^{S P}\right)<\hat{K}^{S P}$.

The above implies that for fixed costs $\hat{K} \in\left(\hat{K}^{P C}, \hat{K}^{S P}\right)$, the GDAP should be developed (i.e., it is Pareto optimal to do so) but it won't be if the laws prevent producer organizations from exercising any kind of market power. Thus, for $\hat{K} \in\left(\hat{K}^{P C}, \hat{K}^{S P}\right)$ the actual change in social surplus under a social planner $\left(\Delta S S^{S P}(\hat{K})>0\right)$ is strictly greater than under a perfectly competitive GDAP organization $\left(\Delta S S^{P C}(\hat{K})=1_{\hat{K}<\hat{K}^{P C}}\left(\Delta s S^{P C}-\hat{K}\right)=0\right)$. The extreme example of such a situation arises when the total area is not binding (i.e., $A$ is large), in which case $a^{P C}<1$. This is true because $\lambda_{a \leq 1}^{P C}=0$ if $a^{P C}<1$, so (3.10) implies that the net change in producer surplus is zero $\left(\Delta p s^{P C}=A a^{P C}\left\{\left[x^{P C} u^{\prime}\left(A a^{P C} x^{P C}\right)-c\left(x^{P C}, \theta^{P C}\right)\right]-\pi_{c o m}^{*}\right\}=0\right)$. Consequently, the corresponding fixed cost of indifference under competition is zero $\left(\hat{K}^{P C}=0\right)$.

The intuition here is that the social planner takes both consumers and producers into account, whereas the GDAP organization will be able to cover the fixed costs only when producers gain. But producers recognize that they will find it difficult to create economic profits under this perfectly competitive scenario, so they will typically refuse to pay the fixed cost to develop the GDAP. However, one can envision instances where producers might find it optimal to develop the GDAP even under this competitive scenario. Such cases must entail favored areas so small that producers realize that the overall production response is limited without any other form of supply restriction. A possible example might include Kona coffee from Hawaii. 


\subsubsection{Case 2: Monopoly}

When the producer organization can be legally established to behave as a monopoly, individual producers have no choice regarding output per acre $(x)$, the share of farmland devoted to GDAP production (a), or the production cost parameter $\theta$. Individual producers must set up such quantities at the levels determined by the organization so as to maximize producer surplus. Here the word monopoly needs to be interpreted with caution. It reflects market power over the GDAP, not the commodity product. The strength of the monopolist's power is therefore only as strong as the degree of differentiation achieved by the GDAP organization.

The corresponding FOCs evaluated at the market-clearing quantities are (3.12) through (3.14):

$$
\frac{\partial \Delta p s^{M O}}{\partial x}=A a^{M O}\left[A a^{M O} x^{M O} u^{\prime \prime}\left(A a^{M O} x^{M O}\right)+u^{\prime}\left(A a^{M O} x^{M O}\right)-c_{1}\left(x^{M O}, \theta^{M O}\right)\right]=0
$$

$$
\frac{\partial \Delta p s^{M O}}{\partial a}=A^{2} a^{M O}\left(x^{M O}\right)^{2} u^{\prime \prime}\left(A a^{M O} x^{M O}\right)
$$

$$
+A\left[x^{M O} u^{\prime}\left(A a^{M O} x^{M O}\right)-c\left(x^{M O}, \theta^{M O}\right)\right]-A \pi_{c o m}^{*}-\lambda_{a \leq 1}^{M O}=0,
$$

(3.14) $\frac{\partial \Delta p s^{M O}}{\partial \theta}=-A a^{M O} c_{2}\left(x^{M O}, \theta^{M O}\right)+\lambda_{\theta \geq \underline{\theta}}^{M O}=0$,

where superscript "MO" denotes optimal values under monopoly. FOC (3.14) implies that $\theta^{\mathrm{MO}}=$ $\underline{\theta}$, i.e., like the social planner and the perfectly competitive organization, the monopoly will 
never find it optimal to "artificially" raise production costs. However, FOCs (3.12) and (3.13) have an extra term involving $u^{\prime \prime}(\cdot)<0$ compared to the perfectly competitive counterparts (3.9) and (3.10), respectively. The term $u^{\prime \prime}(\cdot)<0$ represents the effect of a marginal increase in the amount of GDAP sold on its own equilibrium price. As a result, expressions (3.12) and (3.14) would be negative if they were evaluated at the perfectly competitive outcomes $\left(a^{P C}\right.$ and $\left.x^{P C}\right)$. Therefore, relative to perfect competition, the monopoly produces less GDAP per acre and uses fewer acres to produce it.

Since the monopoly solution yields the maximum attainable producer surplus and the corresponding FOCs are different from the perfectly competitive FOCs, it must be the case that $\Delta p s^{M O}>\Delta p s^{P C}$, which in turn implies that the fixed costs of indifference are such that $\hat{K}^{M O}>$ $\hat{K}^{P C}$, where $\hat{K}^{M O} \equiv \Delta p s^{M O}$. Hence, for $\hat{K} \in\left(\hat{K}^{P C}, \hat{K}^{M O}\right)$, society is better off with laws allowing the producer organization to behave as a monopoly rather than completely banning anticompetitive behavior (i.e., $\Delta S S^{M O}(\hat{K})>\Delta S S^{P C}(\hat{K})=0$, where $\Delta S S^{M O}(\hat{K})=$ $\left.1_{\hat{K}<\hat{K}^{M O}}\left(\Delta s s^{M O}-\hat{K}\right)\right)$

By a similar argument, ${ }^{8}$ it is also clear that $\Delta s s^{S P}>\Delta s s^{M O}, \hat{K}^{S P}>\hat{K}^{M O}$, and $\Delta S S^{S P}(\hat{K})>\Delta S S^{M O}(\hat{K})$ for $\hat{K}<\hat{K}^{S P}{ }^{9}$ The loss in social welfare associated with the monopoly relative to the social planner's solution is due to the reduction in output per acre and the number of acres used. These tools are used by the monopolist to extract surplus from consumers. The additional surplus extracted from consumers by the monopoly explains the higher indifference fixed cost when compared to the perfectly competitive producer organization.

\footnotetext{
${ }^{8}$ Note that the social planner's objective is to maximize social welfare, and that the corresponding FOCs are different from the monopoly FOCs.

${ }^{9}$ For $\hat{K}>\hat{K}^{S P}, \Delta S S^{S P}(\hat{K})=\Delta S S^{M O}(\hat{K})=0$.
} 


\subsubsection{Case 3: Organizations that Control Both Land and Production Practices}

Here we consider a producer organization that allows individual producers to choose the per-acre GDAP output level but controls the share of farmland that producers can devote to the GDAP and may impose production regulations that are more stringent than necessary in order to maximize producer surplus. This type of organization may emerge when it is illegal for the organization to behave as a monopoly, but the laws may allow it some control over supply.

Conceptually, the optimal values for the GDAP share and production regulations are obtained in two steps. However, as can be seen from Figure 1, we model the decision process as if these decisions are made simultaneously. The first step consists of finding the optimal level of output per acre from the individual producer's perspective, conditional on the acreage and production regulation restrictions $x^{*}(P, a, \theta)$. The second step consists of maximizing producer surplus with respect to acreage and production regulations, taking into account the optimal individual producer's response function $x^{*}(P, a, \theta)$.

The aforementioned two-step procedure implies that, under market-clearing conditions, the following FOCs must be simultaneously satisfied at the optimum:

(3.15) $\frac{\partial \Delta \pi^{a \theta}}{\partial x}=a^{a \theta}\left[u^{\prime}\left(A a^{a \theta} x^{a \theta}\right)-c_{1}\left(x^{a \theta}, \theta^{a \theta}\right)\right]=0$,

$$
\begin{aligned}
& \frac{\partial \Delta p s^{a \theta}}{\partial a}=A a^{a \theta}\left(x^{a \theta}\right)^{2} u^{\prime \prime}\left(A a^{a \theta} x^{a \theta}\right)\left(A-\lambda_{\partial \pi^{a \theta} / \partial x=0}^{a \theta}\right) \\
& +A\left[x^{a \theta} u^{\prime}\left(A a^{a \theta} x^{a \theta}\right)-c\left(x^{a \theta}, \theta^{a \theta}\right)\right]-A \pi_{c o m}^{*}-\lambda_{a \leq 1}^{a \theta}=0,
\end{aligned}
$$


(3.17) $\frac{\partial \Delta p s^{a \theta}}{\partial \theta}=\lambda_{\partial \pi^{a \theta} / \partial x=0}^{a \theta} a^{a \theta} x^{a \theta} c_{12}\left(x^{a \theta}, \theta^{a \theta}\right)-A a^{a \theta} c_{2}\left(x^{a \theta}, \theta^{a \theta}\right)+\lambda_{\theta \geq \underline{\theta}}^{a \theta}=0$,

where superscript " $a \theta$ ' denotes optimal market-clearing values under the production organization that controls acreage and production regulations, $x^{a \theta} \equiv x^{*}\left[u^{\prime}\left(A a^{a \theta} x^{a \theta}\right), a^{a \theta}, \theta^{a \theta}\right]$, and $\lambda_{\partial \pi^{a /} / \partial x=0}^{a \theta}>0$ is the Lagrangian multiplier corresponding to constraint (3.15). FOC (3.15) corresponds to the first step mentioned above, whereas FOCs (3.16) and (3.17) arise from the second step.

A significant difference between the " $a \theta$ " organization and all of previous scenarios is that it may be optimal for the producer organization to raise artificially the costs of production by setting parameter $\theta$ higher than the minimum necessary $\underline{\theta}$. This is true because, unlike its counterparts for the previously examined regimes, FOC (3.17) includes the strictly positive term involving $\lambda_{\partial \pi^{a \theta} / \partial x=0}^{a \theta}$. Lagrangian $\lambda_{\partial \pi^{a \theta} / \partial x=0}^{a \theta}$ is positive because relaxing constraint (3.15) to (3.12) would allow the " $a \theta$ ' organization to behave like a monopoly and increase producer surplus.

Conditions (3.15) through (3.17) are different from the FOCs that achieve the maximum possible producer surplus (i.e., (3.11) through (3.14)). By standard optimization results it follows that $\Delta p s^{a \theta}<\Delta p s^{M O}$, so the indifference fixed costs for the organization setting acreage and regulating production practices are strictly smaller than the indifference fixed costs for the monopoly $\left(\hat{K}^{a \theta}<\hat{K}^{M O}\right.$, where $\left.\hat{K}^{a \theta} \equiv \Delta p s^{a \theta}\right)$. By the same reasoning, when $a^{a \theta}<1$ and/or $\theta^{a \theta}>\underline{\theta}$ it must also be the case that $\Delta p s^{a \theta}>\Delta p s^{P C}$ and $\hat{K}^{a \theta}>\hat{K}^{P C}$. However, when both $a^{a \theta}=1$ and $\theta^{a \theta}=$ $\underline{\theta}$ hold (as could happen if, e.g., $A$ is small enough), the allocations under the " $a \theta$ ' organization are the same as under perfect competition, so in such instances $\Delta p s^{a \theta}=\Delta p s^{P C}$ and $\hat{K}^{a \theta}=\hat{K}^{P C}$. 


\subsubsection{Case 4: Organizations Controlling only Land}

A scenario involving a lesser degree of market power by the producer organization than Case 3 is one in which the organization controls the amount of farmland allocated to the GDAP (a) so as to maximize producer surplus, but individual producers choose the profit-maximizing levels of output per acre $(x)$ and the production practices $(\theta \geq \underline{\theta})$. Similar to Case 3 , the solution to such a problem can be obtained in two steps. The resulting market-clearing allocations must simultaneously solve FOCs (3.18) through (3.20) (with (3.18) and (3.20) corresponding to the first step and (3.19) to the second step):

$$
\frac{\partial \Delta \pi^{a}}{\partial x}=a^{a}\left[u^{\prime}\left(A a^{a} x^{a}\right)-c_{1}\left(x^{a}, \theta^{a}\right)\right]=0
$$

$$
\frac{\partial \Delta p s^{a}}{\partial a}=A a^{a}\left(x^{a}\right)^{2} u^{\prime \prime}\left(A a^{a} x^{a}\right)\left(A-a^{a} \lambda_{\partial \pi^{a} / \partial x=0}^{a}\right)
$$

$$
+A\left[x^{a} u^{\prime}\left(A a^{a} x^{a}\right)-c\left(x^{a}, \theta^{a}\right)\right]-A \pi_{c o m}^{*}-\lambda_{a \leq 1}^{a}=0 .
$$

(3.20) $\frac{\partial \Delta \pi^{a}}{\partial \theta}=-a^{a} c_{2}\left(x^{a}, \theta^{a}\right)+\lambda_{\theta \geq \underline{\theta}}^{a}=0$,

In (3.18)-(3.20), superscript " $a$ " denotes the solution values corresponding to the GDAP producer organization that only controls acreage.

From (3.20), it is clear that individual producers set production practices at the lowest level compatible with obtaining the $\operatorname{GDAP}\left(\theta^{a}=\underline{\theta}\right)$. Further, comparison with the FOCs for the 
perfectly competitive scenario reveals that the only difference regards the acreage FOCs (3.10) and (3.19). Thus, if $a^{a}=1$ (which may happen if, e.g., $A$ is sufficiently small), it is optimal for the GDAP organization to not restrict acreage, in which case the allocation under this type of arrangement will be identical to the allocation under perfect competition. That is, if $a^{a}=1, \Delta p s^{a}$ $=\Delta p s^{P C}$ and $\hat{K}^{a}=\hat{K}^{P C}$, where $\hat{K}^{a} \equiv \Delta p s^{a}$. In contrast, if $a^{a}<1, \Delta p s^{a}>\Delta p s^{P C}$ and $\hat{K}^{a}>\hat{K}^{P C} \cdot{ }^{10}$

Note also that the " $a$ " organization is equivalent to an " $a \theta$ ' organization restricted to have $\theta^{a \theta}=$ $\underline{\theta}$. Thus, $\Delta p s^{a}<\Delta p s^{a \theta}$ and $\hat{K}^{a}<\hat{K}^{a \theta}$ if $\theta^{a \theta}>\underline{\theta}$, and $\Delta p s^{a}=\Delta p s^{a \theta}$ and $\hat{K}^{a}=\hat{K}^{a \theta}$ otherwise.

\subsubsection{Case 5: Organizations Controlling only Production Practices}

Finally, consider the case of a producer organization that allows individual producers to set their GDAP output per acre and the acreage allocations but controls the production regulations so as to maximize producer surplus. As in Cases 3 and 4, the resulting allocations can be obtained conceptually by means of a two-step procedure. Under market-clearing conditions, such allocations must simultaneously solve FOCs (3.21) through (3.23) (with (3.21) and (3.22) corresponding to the first step and (3.23) to the second step):

(3.21) $\frac{\partial \Delta \pi^{\theta}}{\partial x}=a^{\theta}\left[u^{\prime}\left(A a^{\theta} x^{\theta}\right)-c_{1}\left(x^{\theta}, \theta^{\theta}\right)\right]=0$,

$$
\frac{\partial \Delta \pi^{\theta}}{\partial a}=\left[x^{\theta} u^{\prime}\left(A a^{\theta} x^{\theta}\right)-c\left(x^{\theta}, \theta^{\theta}\right)\right]-\pi_{c o m}^{*}-\lambda_{a \leq 1}^{\theta}=0
$$

\footnotetext{
${ }^{10}$ Note that FOC (3.19) is different from FOC (3.10) if $a^{a}<1$. Hence, in such instances, standard optimization results imply that $\Delta p s^{a}>\Delta p s^{P C}$.
} 


$$
\frac{\partial \Delta p s^{\theta}}{\partial \theta}=\lambda_{\partial \pi^{\theta} / \partial x=0}^{\theta} a^{\theta} x^{\theta} c_{12}\left(x^{\theta}, \theta^{\theta}\right)-a^{\theta} c_{2}\left(x^{\theta}, \theta^{\theta}\right)\left(A-\lambda_{\partial \pi^{\theta} / \partial a=0}^{\theta}\right)+\lambda_{\theta \geq \underline{\theta}}^{\theta}=0
$$

where superscript " $\theta$ " is used to represent market-clearing optimal allocations for the producer organization that only restrict production practices. Lagrangian multiplier $\lambda_{\partial \pi^{\theta} / \partial a=0}^{\theta}>0$ corresponds to restriction (3.22) and is positive because relaxing this restriction would allow the organization to increase producer surplus by behaving like an " $a \theta$ ' organization.

Comparison of FOCs (3.23) and (3.17) shows that the " $\theta$ " organization's incentives to make production practices costlier than strictly necessary (i.e., $\theta^{\theta}>\underline{\theta}$ ) are even stronger than for the " $a \theta$ ' organization, as for the former organization $\theta$ is the only tool available to enhance producer surplus. Given that the " $\theta$ ' organization can be considered an " $a \theta$ " organization without control over acreage, or a perfectly competitive organization with control over $\theta$, it must be the case that $\Delta p s^{a \theta} \geq \Delta p s^{\theta} \geq \Delta p s^{P C}$ and $\hat{K}^{a \theta} \geq \hat{K}^{\theta} \geq \hat{K}^{P C}$, where $\hat{K}^{\theta} \equiv \Delta p s^{\theta}$. Inequalities are strict if the respective organizations effectively use their control variables (e.g., $\Delta p s^{\theta}>\Delta p s^{P C}$ and $\hat{K}^{\theta}>\hat{K}^{P C}$ if $\theta^{\theta}>\theta^{P C}=\underline{\theta}$.

Note also that the " $\theta$ " organization will not be conducive to development of the GDAP if $a^{\theta}<1$, because in such instances $\lambda_{a \leq 1}^{\theta}=0$, so (3.22) implies that the net producer surplus change is zero $\left(\Delta p s^{\theta}=A a^{\theta}\left\{\left[x^{\theta} u^{\prime}\left(A a^{\theta} x^{\theta}\right)-c\left(x^{\theta}, \theta^{\theta}\right)\right]-\pi_{c o m}^{*}\right\}=0\right)$. Consequently, the fixed cost of indifference is zero ( $\left.\hat{K}^{\theta}=0\right)$ if acreage does not become binding under the " $\theta$ ' organization.

\section{Further Discussion}

Some of the main results from the preceding sections can be summarized as Proposition 1. 
Proposition 1: The fixed costs of indifference for the social planner and the alternative types of producer organizations satisfy the following inequalities:

$$
\begin{gathered}
\hat{K}^{S P}>\hat{K}^{M O}>\hat{K}^{a \theta} \geq \hat{K}^{j} \geq \hat{K}^{P C}, j=a, \theta . \\
\hat{K}^{a} \leq \geq \hat{K}^{\theta} .
\end{gathered}
$$

According to Proposition 1, ceteris paribus GDAP development is least likely to occur where the laws forbid any departure from perfect competition, and it is most likely to take place where the legal environment allows the organization to behave like a monopoly. The likelihood that the GDAP will be developed in legal environments in between those two extremes (i.e., allowing " $a \theta$, , " $a$, , or " $\theta$ ' organizations) is intermediate. Producer organizations with control over either acreage only or production practices only are more likely to develop the GDAP than the perfectly competitive structure, but less so than the " $a \theta$ ' organization.

For the alternative types of organizations, the rankings shown in Proposition 1 are derived from the rankings of the respective changes in producer surpluses. Therefore, the latter mimic the rankings in Proposition 1, i.e., $\Delta p s^{M O}>\Delta p s^{a \theta} \geq \Delta p s^{j} \geq \Delta p s^{P C}$ for $j=a, \theta \cdot{ }^{11}$ However, as discussed next, rankings of the alternative types of organizations from the perspective of social welfare are more ambiguous.

\subsection{Changes in Social Welfare Conditional on the GDAP Having Been Developed}

Insights about the rankings of societal surplus under the alternative organizations can be obtained by noting that each of these rankings is equivalent to a constrained social planner optimization

\footnotetext{
${ }^{11}$ Available from the authors is a proof that if both the " $a$ " and " $\theta$ ' organizations yield the same aggregate output, a sufficient condition for $\Delta p s^{a}>\Delta p s^{\theta}$ (i.e., $\hat{K}^{a}>\hat{K}^{\theta}$ and $\Delta s s^{a}>\Delta s s^{\theta}$ ) is that the variable cost function be multiplicative in $\theta$ (i.e., $c(x, \theta)=f(x) g(\theta)$ ).
} 
problem, where the constraints correspond to the conditions that must be satisfied under the corresponding organization. For example, take the perfectly competitive case. Conditional on having developed the GDAP at time $t=2$, the "PC" constrained social planner problem consists of maximizing $\Delta s s$ with respect to $(x, a, \theta)$, subject to FOCs (3.9) through (3.11). As discussed earlier, however, the latter FOCs are equivalent to the unconstrained social planner FOCs (3.6) through (3.8). In other words, the constraints arising from the perfectly competitive FOCs in effect impose no restrictions on the social planner, and this is denoted in Table 1 by the labels "no restriction" on the first three cells of the perfect competition row.

The fourth column corresponds to the restriction that aggregate output be obtained at minimum cost, which under perfect competition does not effectively constrain the social planner. To see this, consider the problem of minimizing total GDAP variable costs $\left\{A a\left[c(x, \theta)+\pi_{\text {com }}^{*}\right]\right\}$ with respect to $x, a$, and $\theta$, subject to the restriction that aggregate output $(A a x)$ be equal or greater than some fixed level $\underline{X}$. The solution yields $\theta^{m c}=\underline{\theta}$ and $\lambda^{m c}=A\left\{x^{m c} c_{1}\left(x^{m c}, \underline{\theta}\right)-\left[c\left(x^{m c}\right.\right.\right.$, $\left.\left.\left.\underline{\theta})+\pi_{\text {com }}^{*}\right)\right]\right\} \geq 0$, where $\lambda^{m c}$ is the Lagrangian corresponding to the restriction $1 \geq a^{m c}$ and superscript " $m c$ " denotes cost-minimizing values. Lagrangian $\lambda^{m c}$ represents the decrease in total costs of producing $\underline{X}$ if the restriction that $1 \geq a^{m c}$ were relaxed by an infinitesimal amount. It is clear from the respective FOCs that the cost-minimization conditions are always satisfied for the social planner, the perfectly competitive organization, and the monopoly but not necessarily so by the " $a \theta$," " $a$," and " $\theta$ ' organizations. Thus, even though such organizations have less market power than a monopoly and therefore yield smaller "standard" deadweight losses (i.e., losses stemming from reduced output), they may also lead to technological efficiency losses that the monopoly solution does not have. 
Table 1. Restrictions Imposed on a Social Planner's Optimization Problem under Different Types of Producer Organizations

\begin{tabular}{|l|c|c|c|c|}
\hline Producer Organization & \multicolumn{3}{|c|}{ Conditions Corresponding to: } \\
\cline { 2 - 5 } & Output & Land & Production & Cost \\
& per Acre & Allocation & Practices & Minimization \\
& $(x)$ & $(a)$ & $(\theta)$ & No restriction \\
Merfect Competition & No restriction & No restriction & No restriction & No restriction \\
" $a$ " Organization & Restriction & Possible restr. & No restriction & Possible restr. \\
" $a \theta$ ' Organization & No restriction & Possible restr. & No restriction & Possible restr. \\
“ $\theta$ ' Organization & No restriction & No restriction & Possible restr. & Possible restr. \\
\hline
\end{tabular}

Given that, as just discussed, imposing a perfectly competitive behavior on the social planner does not effectively restrict him, it can be concluded that $\Delta s s^{P C}=\Delta p s^{S P}$. Analogously, the social planner problem under monopoly involves maximization of $\Delta s s$ subject to the monopoly FOCs (3.12) through (3.14). In this instance, FOC (3.14) in effect does not restrict the social planner because, as shown before, $\theta^{M O}=\theta^{S P}=\underline{\theta}$. However, FOC (3.12) does restrict the social planner's choice of $x$, and FOC (3.13) may (if $a^{M O}=1$ ) or may not (if $a^{M O}<1$ ) restrict the social planner's choice of $a$. These results are summarized in Table 1 by the labels "restriction," "possible restriction," and "no restriction" in the cells corresponding to $x, a$, and $\theta$, respectively, of the monopoly row. Because FOC (3.12) imposes a binding constraint on the social planner's optimization, it follows that the unconstrained solution strictly dominates the constrained solution (i.e., $\Delta s S^{S P}>\Delta p s^{M O}$ ). 
The labels "possible restriction" and "no restriction" in the other cells of Table 1 are obtained following a similar reasoning. It can be seen that the restrictions under the " $a \theta$," " $a$," and " $\theta$ ' organizations need not be binding for the social planner. If they are (not) binding, the respective social surpluses are strictly less than (the same as) the social surplus for the unrestricted social planner, i.e., $\Delta s s^{S P} \geq \Delta s s^{j}$ for $j=a \theta, a, \theta$. Further, it is not possible to rank the social surpluses under monopoly and the " $a \theta$, , " $a$, , " $\theta$ ' organizations relative to each other ( $\Delta s s^{i}$ $\leq \geq \Delta s s^{j}$ for $i=M O, a \theta, a, \theta$, and $\left.j=M O, a \theta, a, \theta\right)$ because the restrictions need not be nested. The preceding results about social surplus are summarized as Proposition 2 below.

Proposition 2. Conditional on the GDAP having been developed at time $t=2$, the changes in social welfare corresponding to the unrestricted Pareto optimum and the alternative types of producer organizations satisfy the following inequalities:

$$
\begin{gathered}
\Delta s s^{S P}=\Delta s s^{P C}>\Delta s s^{M O}>0 . \\
\Delta s s^{S P}=\Delta s s^{P C} \geq \Delta s s^{j}>0, j=a \theta, a, \theta . \\
\Delta s s^{i} \leq \geq \Delta s s^{j}, \text { for } i=M O, a \theta, a, \theta, \text { and } j=M O, a \theta, a, \theta .
\end{gathered}
$$

Proposition 2 concerns ex post changes in social welfare, i.e., changes after having developed the GDAP. However, as indicated by Proposition 1, the alternative types of producer organizations may be quite different in terms of the likelihood of leading to development of the GDAP in the first place. For this reason, it is essential to evaluate the ex ante changes in social welfare, i.e., the changes before development of the GDAP. In other words, Proposition 2 involves the division of an existing pie, but it is essential to determine whether the pie will exist to begin with. 


\subsection{Ex Ante Changes in Social Welfare}

Changes in ex ante social surplus depend on the fixed development costs of the GDAP and (when measured in monetary units of time $t=3$ ) are given by $\Delta S S^{j}(\hat{K})=1_{\hat{K}<\hat{K}^{j}}\left(\Delta s s_{G I}^{j}-\hat{K}\right) \geq 0$ for $j=S P, P C, M O, a \theta, a, \theta$. As discussed earlier in the social planner section, $\Delta S S^{S P}(\hat{K}) \geq 0$ because the social planner will only invest in the GDAP if doing so is conducive to greater social welfare. For each producer organization it is also the case that $\Delta S S^{j}(\hat{K}) \geq 0$, because organization $j$ will develop the organization only if the resulting producer surplus exceeds the fixed investment $\left(\Delta p s^{j}>\hat{K}\right)$. Since consumer surplus is strictly positive, it follows from $\left(2.1^{\prime}\right)$ that $\Delta s s^{j}>\hat{K}$ when organization $j$ invests in the GDAP. Therefore, $\Delta S S^{j}(\hat{K})>0$ if organization $j$ invests in the GDAP and $\Delta S S^{j}(\hat{K})=0$ if it does not.

Combining Propositions 1 and 2 with the results just derived allows us to gain insights about the ex ante changes in social surplus. Some key observations in this regard are summarized as Proposition 3 below.

Proposition 3. From the perspective of time $t=0$, there exists a nonempty set of fixed GDAP development costs $\hat{K} \in\left(\hat{K}^{P C}, \hat{K}^{M O}\right)$ for which

(a) the perfectly competitive organization yields no gains in social surplus (i.e., $\left.\Delta S S^{P C}(\hat{K})=0\right)$

(b) every producer organization with market power yields at least as much social surplus as the perfectly competitive organization (i.e., $\min \left[\Delta S S^{j}(\hat{K})\right.$ for $\left.j=M O, a, \theta, a \theta\right] \geq 0=$ $\left.\Delta S S^{P C}(\hat{K})\right)$ 
(c) there exists a producer organization with market power that yields a strictly greater social surplus than the perfectly competitive organization (i.e., $\max \left[\Delta S S^{j}(\hat{K})\right.$ for $j=M O, a, \theta$, $\left.a \theta]>0=\Delta S S^{P C}(\hat{K})\right)$.

Proposition 3 means that there are situations where legal environments enforcing perfectly competitive behavior on the producer organization will preclude the development of the GDAP even though it would be socially optimal to do so, and where less-restrictive laws regarding anticompetitive behavior will lead to the development of the GDAP and to improvements in social welfare. In other words, whenever anticompetitive laws are sufficiently relaxed so as to induce a GDAP to exist that otherwise would not have existed, there is an increase in welfare. However, whenever such laws provide the producer organization with more supply control than is needed to develop the GDAP, then there may be a possible reduction in total welfare compared to more restrictive anticompetitive regulations.

Counterintuitively, however, Propositions 1 and 2 together imply that there need not be an inverse relationship between the ex ante incentives to invest in GDAP development and the ex post social surplus for the various types of organizations that are not legally constrained to behave competitively. For example, there are circumstances where the " $a \theta$ ' provides both a greater incentive to invest in the GDAP and a larger social surplus ex post than the " $\theta$ " organization $\left(\Delta p s^{a \theta}>\Delta p s^{\theta}\right.$ and $\left.\Delta s s^{a \theta}>\Delta s s^{\theta}\right)$. The reason for this paradoxical result is that the “ $a \theta$, , " $a$, , and " $\theta$ ' organizations may involve substantial technical inefficiencies. 


\section{Implications of the Results for U.S. and EU GDAPs}

The previous results can be applied to draw some implications about GDAPs in the U.S. and the EU. In terms of the proposed model, it is arguably the case that the EU system of geographic indications (GIs) that regulates most of its GDAPs allows for " $a \theta$ ' organizations, whereas in the U.S. only “ $\theta$ ' organizations can exist legally.

EU GIs, known separately as PDO (Protected Designation of Origin), PGI (Protected Geographical Indication), and TSG (Traditional Speciality Guaranteed), were created in 1992 to promote and protect food products (EC 1992). Since then, the EU has approved 684 foods for protection under these designations. In addition, it currently lists 200 applications pending, of which 27 were added in the first six months of 2005 (European Commission 2006). Most of the new European GDAPs have evolved from submissions by producer groups that describe and limit the area within which the new GDAP can be produced. Some of them impose additional control over production practices, and the output of these GDAPs is quite small relative to the commodity market.

In contrast, existing U.S. GDAP rules have been explicitly designed to prohibit acreage control; however, some federal marketing orders do allow post-harvest quality and/or size adjustments that can be viewed as a form of control over production practices. In the U.S., GDAPs are protected as certification marks (U.S. Congress 2003). A certification mark is subject to cancellation if its owner "....refuses to certify or to continue to certify the goods or services of any person who maintains the standards or conditions which such mark certifies" (Hannon 2002, $\S 1306.07)$. By design, certification marks cannot be used to control supply. Another possible supply control mechanism in the U.S. is the use of a trademark; however, as described in Addor 
and Graziou (2002, pp. 869-870), trademarks "bear an individual ownership approach" whereas EU GIs "meet the collective approach."

Note also that although some of the GDAPs in the EU have ancestral origins that predate the enactment of the $1992 \mathrm{EU}$ GI system that regulates most of its GDAPs, many EU GIs such as Scottish Farmed Salmon are of relatively recent origin. Finally, and possibly more controversially, it may also be argued that U.S. producers have had access to information for a long enough time to have optimized their organizations in a way that maximizes producer surplus given the legal constraints. This means that the U.S. marketplace has served as a natural experiment with any GDAP organizations that are likely to be formed having already formed. The situation is different in the EU, because the existing rules controlling the formation of GDAPs have changed several times in recent history. ${ }^{12}$

In the context of our model, the above generalizations imply that the ex post welfare results apply if some of the EU GDAPs predate the GI system. If that were the case, it can be concluded that for these older GDAPs, the 1992 EU GI legislation simply served the purpose of enhancing producers' surplus at the expense of consumers, with a total net loss in societal welfare. In contrast, for the many new EU GDAPs that would not have existed without the GI system, the above generalizations suggest that the recent surge in GDAP formation in the EU has improved societal surplus, and that the institutional incentives that led to the formation of these new GDAPs would enhance producer and consumer surpluses in the U.S. Interestingly, these

\footnotetext{
${ }^{12}$ Reflecting philosophical and legislative differences regarding the ability of the EU to enforce the property right protections of GIs internationally, the U.S. filed a complaint in 2002 with the World Trade Organization (WTO) against the EU policy on grounds that it discriminates against non-EU GIs and that it does not provide sufficient protection to pre-existing U.S. trademarks that may conflict with EU-designated GIs (Josling 2005). The U.S. position with respect to its domestic market is that its trademark laws (in the form of certification marks) adequately protect U.S. and non-U.S. GDAPs alike, and that there is no further need for special property right protection for GDAPs. The resulting WTO panel on GIs (WTO 2005) recently led the EU to amend some points of the EC regulation 2081/92 by the regulation 510/2006 (EC 2006) to comply with the agreement on Trade-Related Aspects of Intellectual Property Rights (TRIPS) and recognize non-EU GIs and protect third-party trademarks.
} 
implications are in direct opposition to the current position of the U.S. government and U.S. farm groups. For example the official position of the American Farm Bureau is that "We are strongly opposed to GI's" (Stallman 2003).

Besides suggesting that the EU GI system weakly dominates the U.S. GDAP legislation in terms of producer surplus, our results allow for the counterintuitive possibility that the EU system may dominate the U.S. one even in terms of ex post social surplus. The latter implication is possible because the U.S. approach provides producer organizations with fewer instruments to control supply, and in so doing may induce such organizations to distort production practices in such a way that output is obtained in a less efficient manner than it could otherwise.

Put succinctly, our results strongly suggest that from the perspective of both producer surplus and societal surplus, the U.S. GDAP legislation (based on certification marks and marketing orders) is not equivalent to the EU GI system.

\section{Concluding Remarks}

Individual firms who have adequate intellectual property right protection have the incentive to innovate and market products because they realize that they can capture the rents associated with success. This incentive does not exist in commodity agriculture because rational producers realize that other producers will expand production in response to any economic rents that result from successful innovations.

The present study applies standard welfare analysis to the case in which atomistic producers are involved in the creation of geographically differentiated agricultural products (GDAPs). It is shown that, as expected, the stronger the level of property right protection, the greater the incentives for producers to develop GDAPs that do not yet exist. Counterintuitively, 
stronger property right protection for producer organizations may be welfare enhancing even after a GDAP has been developed. The reason for this somewhat paradoxical result is that GDAP legislation aimed at curtailing the market power of producer organizations may induce large technological distortions.

In the context of GDAP legislation in the EU and the U.S., we argue that, to the extent that the assumptions made in the advocated model are correct, the EU rules are likely to dominate in terms of ex ante societal surplus (i.e., surplus that accounts for the incentives to develop GDAPs). A natural extension of this logic is that the U.S. has seen about as much innovation as it is likely to see under the GDAP rules it has in place. Therefore, any extension of such rules providing producer organizations with stronger control over supply should lead to an increase in the formation of GDAP organizations and ultimately in social welfare. This result is in direct opposition to the current position of the U.S. government and U.S. commodity groups. 


\section{References}

Addor, F., and A. Graziou. 2002. "Geographic Indications beyond Wine and Spirits.” The Journal of World Intellectual Property 5(6):865-896.

European Commission. 2006. Agriculture and Food, Food Quality, PDO/PGI/TSG updates of 06-03-06, 07-02-06, 20-06-05,03,05,05, Available at http://europa.eu.int/comm/agriculture/foodqual/protec/applications/index en.htm (accessed March 8, 2006).

EC (European Communities). 1992. “Council Regulation No. 2081/92 of 14 July 1992 on the Protection of Geographical Indications and Designations of Origin for Agricultural Products and Foodstuffs.” (EC Regulation 2081/92). Office for Official Publications of the European Communities, May 1, 2004.

- 2006. European Council Regulation No. 510/2006 of 20 March 2006 on the protection of geographical indications and designations of origin for agricultural products and foodstuffs. Available at http://europa.eu.int/eur-lex/lex/LexUriServ/site/ en/oj/2006/1_093/1_09320060331en00120025.pdf (accessed April 5).

Hannon, M., ed. 2002. Trademark Manual of Examining Procedure - $3^{\text {rd }}$ Edition, Revision 1. Washington, D.C.: US Commerce Department, Patent and Trademark Office, June 2002. Available at http://www.uspto.gov/web/offices/tac/tmep/ (accessed March 2005).

Hayes, D., S. Lence, and A. Stoppa. 2004. "Farmer-Owned Brands?” Agribusiness: An International Journal 20:269-285.

Hollander, A., S. Monier, and H. Ossard. 1999. "Pleasures of Cockaigne: A Story of Quality Gaps, Market Structure, and Demand of Grading Services.” American Journal of Agricultural Economics 83(2):501-511. 
Josling T. 2005. "What's In a Name? The Economics, Law and Politics of Geographical Indications for Food and Beverages.” November 11, 2005. IIIS Discussion paper 109, Trinity College, Dublin.

Marette, S., and J. Crespi. 2003. "Can Quality Certification Lead to Stable Cartels?” Review of Industrial Organization 23(1, August):43-64.

Stallman, B. 2003. Statement of the American Farm Bureau Federation to the House Agriculture committee regarding World Trade Organization on multilateral trade negotiations and free trade Agreements. June 18.

U.S. Congress. 2003. "The Status of the World Trade Organization Negotiations on Agriculture - Hearings Before the Committee on Agriculture of the House of Representatives on May 21, June 18, and July 22, 2003.” U.S. Government Printing Office, Washington, D.C. USDA (U.S. Department of Agriculture), Agricultural Marketing Service. 2006. Dried Prunes Produced in California; 7 CFR Part 993, Docket No. FV02-993-610, Federal Register Vol. 71, No. 29, Monday, February 13, 2006 pp. 7395 and 7396.

WTO (World Trade Organization). 2005. "Panel Reports Out on Geographical Indications Disputes." March 15, 2005. Geneva. Available at http://www.wto.org/english/news e/ news05_e/panelreport_174_290_e.htm (accessed April 2006).

Zago, A., and D. Pick. 2004. "Labeling Policies in Food Markets: Private Incentives, Public Intervention and Welfare." Journal of Agricultural and Resource Economics 29(1):150169. 